\title{
A Study on the Applicability of HSPF Paddy-RCH for Calculating the Reduction of Agricultural Non-point Pollutants
}

\author{
Shin Hye Jung ${ }^{1 \oplus} \cdot$ Han-Pil Rhee ${ }^{1 \oplus} \cdot$ Ha Sun Hwang ${ }^{2 \odot} \cdot$ Chun Gyeong Yoon $^{1,+\oplus}$ \\ ${ }^{1}$ Department of Environmental Health Science, Konkuk University \\ ${ }^{2}$ Water Environmental Research Department, National Institute of Environmental Research
}

(Received September 15, 2020; Revised November 5, 2020; Accepted November 13, 2020)

Objectives: Non-point source pollution (NPS) reduction has been considered as the first priority in South Korea to achieve acceptable water quality. Among many NPS pollutions, agricultural NPS is one of the major NPS contributor due to its vast area. However, agricultural NPS characterization has not been successful because agricultural NPS has inconsistent water and mass balances, thus has lacking NPS reduction measures. This study assesses applicability of HSPF Paddy-RCH method to estimate agricultural NPS loads in paddy rice field.

Methods: HSPF Paddy-RCH method was developed to simulate water and mass balance in paddy rice field(s). Applicability of the developed method was tested in Gyeseongcheon watershed in Nakdong River basin, South Korea. The study area was selected because there is no other major pollutant source except the paddy fields, but has simple drainage system. HSPF Paddy-RCH method was calibrated in control paddy field with conventional fertilizing condition and applied to two small scale paddy fields ( $89 \%$ and $76 \%$ fertilizing condition). The calibrated HSPF Paddy-RCH method was then tested in small watershed (subbasin) including small paddy fields applied earlier for applicability study of watershed scale.

Results and Discussion: Calibrated HSPF Paddy-RCH method well represented observed flow rates $\left(\mathrm{R}^{2}=0.825\right)$ and water-quality (BOD, T-N, T-P, relative differences $[\%$ diff $]<7.52 \%$ ). Water-quality parameters for the control paddy field showed slower decaying rate than river and stream. The calibrated HSPF Paddy-RCH well represented water and mass balance for the small scale paddy fields with varying fertilizing condition $\left(\mathrm{R}^{2}>0.689\right.$ for flow rate, $\%$ diff $<12.20 \%$ for water quality), as well as for the small scale watershed with large scale paddy fields $\left(\mathrm{R}^{2}>\right.$ 0.693 for flow rate, \%diff $<19.29 \%$ for water quality) could promise.

Conclusions: This applicability study results would suggest that HSPF Paddy-RCH method is a feasible tool to quantify agricultural NPS pollution and to develop reduction measured for paddy rice field.

Keywords: TPLM, Agricultural NPS, Watershed Model, Paddy Field, HSPF Paddy-RCH

The Korean text of this paper can be translated into multiple languages on the website of http:/jksee.or.kr through Google Translator.

\footnotetext{
† Corresponding author E-mail: chunyoonenv@gmail.com Tel: 02-450-3747 Fax: 02-450-2543

(c) 2020, Korean Society of Environmental Engineers
} 


\title{
연구논문
}

\section{농업비점 삭감량 산정을 위한 HSPF Paddy-RCH 적용성에 관한 연구}

\author{
정신혜 $^{1 \oplus} \cdot$ 이한필 $^{1 \oplus} \cdot$ 황하선 $^{2 \odot} \cdot$ 윤춘경 $^{1+\oplus \odot}$ \\ ${ }^{1}$ 건국대학교 환경보건과학과 \\ 2국립환경과학원 물환경연구부
}

목적 : 하천의 목표수질 달성을 위해서는 오염부하 기여도가 높은 비점오염원을 줄이는 것이 우선적으로 행해져야 한다. 많은 비점오염원 중에서도 농업 비점오염원은 광범위한 면적에서 불규칙적으로 배출되는 특성이 있어 오염배 출원의 정량화 및 대책마련이 힘든 실정이다. 이에 본 연구에서는 논 비점오염 배출량 산정을 위해 HSPF Paddy-RCH 모델의 적용성을 평가하였다.

방법: HSPF Paddy-RCH 기법은 논의 담수 및 비담수 상태에서의 물수지 및 물질수지 모의를 위해 HSPF (Hydrological Simulation Program-FORTRAN)의 투수층 모듈(PERLAND)과 하천 모듈(RCHRES)의 기능을 조합하 여 개발되었다. 연구지역은 배수계통이 단순하여 외부로부터의 유입 및 영향이 적은 계성천유역이 선택되었으며, 다양한 시비조건과 다양한 영농조건에 대한 적용성은 각각 필지논( $100 \%, 89 \%, 76 \%$ 시비조건)과 광역논 유역에서 평가하였다.

결과 및 토의: 관행시비조건의 논(필지논, $100 \%$ 시비)에서 HSPF Paddy-RCH 모형의 매개변수를 보정한 결과 논에 서 실측된 유량 $\left(\mathrm{R}^{2}=0.825\right)$ 과 수질(BOD, T-N, T-P, 상대오차 $\left.[\% \mathrm{diff}]<7.52 \%\right)$ 을 잘 모의하는 것으로 나타났다. 보정 된 매개변수는 일반 하천보다 느린 논의 영양물질 분해속도를 잘 반영하고 있었다. 동일 매개변수를 이용하여 다 양한 시비량과 영농조건에 대한 적용성을 평가한 결과 유량과 수질항목 모두 실측값을 잘 모의하는 것으로 나타났 다. 본 연구는 특정지역에 한정된 매개변수이므로 모형의 적용성을 높이기 위해서는 다양한 기후 및 영농특성을 가지는 지역에서 추가적인 연구가 필요할 것으로 판단된다.

결론: 모형의 적용성을 평가한 결과 HSPF Paddy-RCH는 영농조건에 따른 논의 수질개선효과 및 총량관리 삭감부 하량 산정에 효과적인 도구로 사용할 수 있을 것으로 판단된다.

주제어: 오염총량관리, 농업비점오염, 유역모델, 논, HSPF Paddy-RCH

\section{1. 서 론}

오염총량관리는 하천구간별로 설정된 목표수질을 달성· 유지하기 위해 오염물질의 배출량을 허용총량 이내로 관리 하는 제도로 배출량을 줄인 만큼 개발용량이 늘어나는 '선 삭감 후개발'을 적용하기 때문에 배출부하량의 일부를 삭감 하는 것은 총량관리의 핵심 요소라고 할 수 있다.

오염총량관리에서는 유역으로부터 배출되는 오염물질을 배 출형태에 따라 점오염원(Point source)과 비점오염원(Non-point sources)으로 구분하여 관리하는데, 최근 들어 생활계 등 점 오염원에서 배출되는 부하량은 줄어드는 반면 토지계 등 비점오염원에서 배출되는 부하량은 증가하는 추세이다. 낙 동강수계의 경우 전체 배출부하량 중 토지계가 차지하는 비 율이 BOD $60.2 \%$, T-P 55.5\%로 매우 높으나 ${ }^{1)}$, 오염총량관리
를 위한 삭감계획은 대부분 환경기초시설 신·증설, 관로확대, 관로정비, 방류수 수질개선 등 점오염원 배출량에 대한 삭감 이고 비점오염원에 대한 삭감은 상대적으로 부족하였으며, 지속적인 환경기초시설 방류수질의 개선 등으로 더 이상 점 오염원에 대한 삭감여력이 부족한 현실에서 비점오염원에 대 한 삭감노력이 매우 필요한 실정이다. ${ }^{1)}$

비점오염원은 주로 축산계, 토지계 오염원그룹에서 발생 되는데 전, 답 등에서 작물을 재배하는 과정 또는 재배 후 발생되어 배출되는 농업비점 배출은 단위면적당 오염물질 배출량이 대지 지목에 비해 낮으나 면적이 넓어 전체 배출 부하량 중 차지하는 비중이 크다.

이런 이유로 농업비점삭감을 위해 농경지에 살포되는 비 료에 함유된 질소 및 인 등의 성분을 관행(표준)적으로 사 용되는 비료에 포함된 양보다 적게 시비하는 시비량 저감방 
법이나, 배수물꼬를 높게 관리하여 배출부하량을 줄이는 배 수물꼬 관리방법 등에 대해 국내에서도 많은 현장 연구가 이루어지고 있다. ${ }^{2,3)}$

강우발생으로 인한 비점오염원 지표유출 형상은 토지이 용 상태에 많은 영향을 받으며, 다양한 오염물질을 포함하 고 있어, 보다 효과적인 유역의 수질 관리를 위해서 비점오 염원 배출 제어에 대한 관리와 대책이 반드시 필요하다. ${ }^{4)}$ 비점오염원 중 농업 비점오염원을 효과적으로 관리하고 정 책적으로 활용하기 위해서는 다양하게 존재하는 영농 방법 에 따른 농업 비점오염원 배출특성 규명 및 체계적인 정량 화 기법이 마련되어야 한다.

그러나 농업비점오염원은 광범위한 면적에 분포하고 불 특정하게 배출되고, 영농방법도 지역적으로 매우 다양하여 비점오염 배출특성 규명 및 정량화에 어려움 있다. ${ }^{5)}$ 특히 비점오염원 정량화 기법은 장기적인 모니터링을 바탕으로 진행되어야 하지만 비용과 시간, 인력 등이 많이 소요되어 실질적으로 수행하기 어려운 문제점이 있다. 이러한 문제점 을 보완하기 위해 국내·외에서는 다양한 유역 유출모델을 활용하여 비점오염원 저감 연구를 수행 중에 있다.

Lee et al. $(2007)^{6)}$ 이 AGNPS 모형을 이용하여 논의 시비 량을 $10 \%$ 30\%로 단계적으로 절감할 경우 비점 배출부하량 의 저감 효율을 나타내었으며, Han et al. (2008) $)^{7)}$ 은 비점오 염원 모형인 CREAMS-PADDY 모형을 이용하여 관행 시비 량의 $10 \%, 20 \%, 30 \%$, 표준시비량의 $30 \%$ 를 감소 시비하여 발생부하량 저감 효과를 분석하였고, Song et al. $(2012)^{8)}$ 은 시비량 감소에 따른 배출부하량의 변화를 고찰하기 위해 관 행시비량에서 표준시비량으로 시비량 저감시 배출부하량을 CREAMS-PADDY 모형으로 모의한 바 있다.

Lee et al. (2018) ${ }^{9)}$ 등은 농촌 유역에서 농업용 저수지와 논 기작을 고려한 수문 및 수질 모의를 위해 HSPF, MASA, CREAMS-PADDY 모형을 연계한 HSPF-MASA-CREAMSPADDY 연계 시스템을 구축하여 설성천 유역을 대상으로 시스템을 적용하여 유역말단에서의 유량과 오염물질 부하량을 산정 하였고, 이를 저수지와 논 기작을 고려하지 않은 경우의 수 문 및 수질 모의 결과와 비교하여 적용성을 평가한 바 있으 며, Jung et al. (2019) ${ }^{10)}$ 은 기존의 모델을 이용한 접근이 논 담수의 모의에 있어서 직접적으로 물량을 다루기보다는 특 정 변수들을 대체하여 간접적으로 모의하거나, 지표하와 연 계된 수문현상을 모의하는데 한계를 가진 기존의 모델접근 을 보완하여 $\mathrm{HSPF}$ 의 기본 모듈과 그 전달경로의 재구성을 포함한 Paddy-RCH 기법을 개발하여 논의 작물재배 특성에 따른 담수 및 비담수 상태에서 물과 오염물질 거동을 재현 할 수 있도록 한 바 있다. 배수물꼬를 달리하는 시범논에 대 한 적용성을 평가한 바 있다. 이후 HSPF Paddy-RCH 기법 은, 설성천 유역에서 배수물꼬 변화에 따른 연중 유출량과 오염물질 변화를 예측하기 위해 적용된 바 있으며, 일모작
지역에서 다양한 조건으로 운영된 논과 유역 적용을 통해 기법의 적정성 및 활용성을 검증하였다. ${ }^{11)}$

본 연구는 논에서 측정된 물수지 및 물질수지 자료를 이 용하여 HSPF Paddy-RCH모델을 보정하고 보정된 반응계수 를 시비량을 달리하는 필지논과 광역논에 적용하여 측정자 료와 비교함으로써, 농업비점 삭감량 평가를 위한 $\mathrm{HSPF}$ Paddy-RCH의 적용성을 평가하고자 한다.

\section{2. 연구방법}

\section{1. 연구대상지역}

연구대상지역은 경상남도 창녕군 장마면에 위치한 구획 화된 농경지로 오염총량관리 단위유역으로는 낙본I 단위유 역에 위치한 계성천 유역의 일부(135.0 ha)이며, 이 중 약 $37.9 \%$ 가 논 지역으로 이루어져 있는데(Fig. 1(b)), 이는 임야 및 수역을 제하고 실제 인간활동이 이루어지는 $90.2 \mathrm{ha}$ (시가 화 건조지역 $16.1 \mathrm{ha}$, 논 $51.1 \mathrm{ha}$, 밭 $18.5 \mathrm{ha}$, 나지 $4.5 \mathrm{ha}$ ) 중 약 $56.7 \%$ 를 차지하고 있다.

일반적인 논농사 지역은 농업용수 공급, 인위적 배수뿐만 아니라, 농업회귀수로 인해 강우유출수의 자연적 흐름과 매 우 다른 특성을 나타내고 있어 비교적 배수계통이 단순하여 외부로부터의 유입 및 영향이 적은 지역을 연구대상 지역으 로 선정하였다.

연구대상지역에는 시비량 차이에 따른 농경지 내 물수지 및 물질수지 변화를 파악하기 위한 3 개의 필지논과 2 개의 광역논 유역으로 구성되어 있다. 필지논은 관행시비 조건인 대조구(CPF, Control Paddy Field)와 관행시비 대비 $11 \%$ 를 저감하여 시비한 실험구(SPF-1, Small scale Paddy Field), $24 \%$ 를 저감하여 시비한 실험구(SPF-2)로 구성하였으며(Fig. 1(c)), 광역논 유역은 최상류로부터 소하천을 따라 설치되 어 있는 8 개의 주요 농배수로 중 $\mathrm{W} 1$ 지점을 기준으로 2 개 의 광역논(상류 광역논(LPF 1), 하류 광역논(LPF 2)) 유역 으로 구성하였다. 일반적인 현장실험연구에서는 시비량을 일률적으로 증감시키나, 본 연구에서는 비료의 종류, 기대 수확량 등 최대한 실제 적용가능한 영농조건을 유지하고 자 하였으며 현지 영농인의 조언을 받아 최적의 시비량의 차이를 두었다.

3 개의 필지논에서는 강우, 관개, 침투, 물꼬배출에 따른 유량과 BOD, T-N, T-P 수질을 측정하였으며(Fig. 1(c)), 2개 의 광역논에서는 유역단위의 적용성을 평가하기 위하여 광 역논 유역의 경계 지점인 $\mathrm{W} 1$ 과 $\mathrm{W} 2$ 지점에서 유량과 $\mathrm{BOD}$, T-N, T-P 수질을 측정하였다(Fig. 1(a)).

연구지역의 관행 시비는 6월 8일 써레질과 함께 기비를 시비를 하였으며 7월 13일 요소비료는 추가 시비하여 농경 지에 살포된 질소 $117 \mathrm{~kg} / \mathrm{ha}$ 이며, 인 $72 \mathrm{~kg} / \mathrm{ha}$ 를 비료로 사 용하였다. 실험구인 SPF-1과 SPF-2에는 관행시비량 대비 


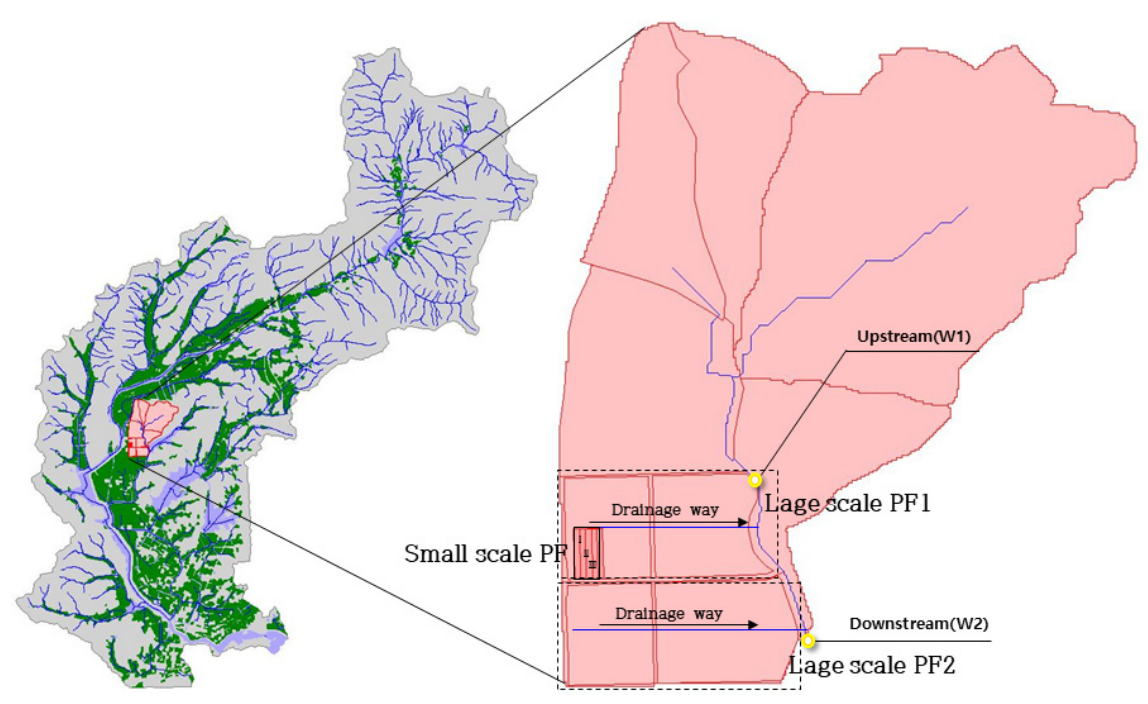

(a) Study area

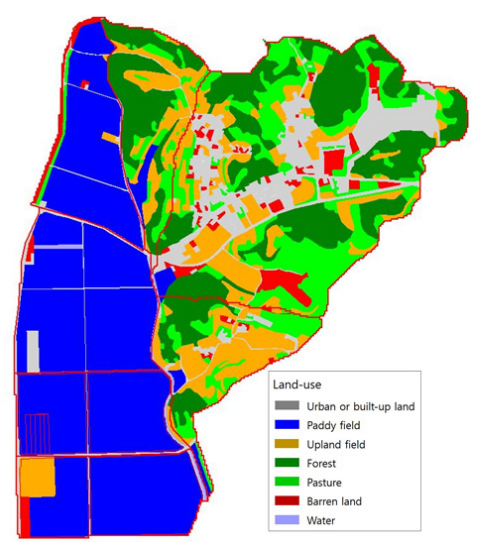

(b) Landuse of study area

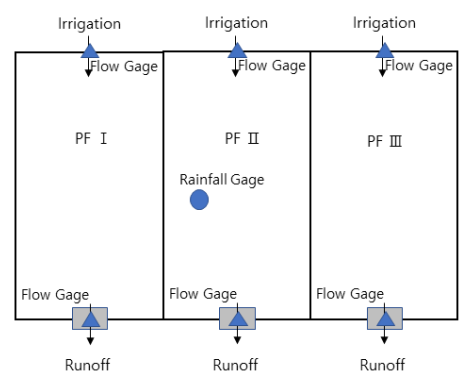

(c) Small-scale paddy field

Fig. 1. Monitoring points of study area.

각각 $89 \%, 76 \%$ 를 시비하였다. ${ }^{12)}$

필지논의 토양입도는 시비관리 $0 \sim 20 \mathrm{~cm}$ 심도에서 모래 $62.04 \%$, 실트 $23.20 \%$, 점토 $14.76 \%$ 이며, $20 ~ 40 \mathrm{~cm}$ 심도에서 모래 $63.40 \%$, 실트 $25.32 \%$, 점토 $11.28 \%$ 으로 이루어진 토양 이며, 두 토층 모두 토양분류표에 따른 Sandy loam이다.

\subsection{HSPF Paddy-RCH}

우리나라는 쌀을 주식으로 하는 특성상 논으로부터 배출 되는 비점오염물질의 기여율이 높은데, 외국에서 개발된 유 역모델은 일반적으로 담수와 비담수상태가 공존하는 논의 특성을 반영하는데 한계가 있다. 현재 수질오염총량관리를 비롯한 유역관리제도의 안정적 시행과 발전을 위해서는 농 업비점오염물질 배출기작을 영농특성을 고려하여 적절히 모의하고 이를 이용하여 $\mathrm{BMP}$ 등 다양한 삭감시나리오에 따른 저감 효과를 예측하는 것이 매우 중요하다.

HSPF Paddy-RCHRES (HSPF Paddy-RCH) 모의체계는 HSPF의 PERLND 모듈과 RCHRES 모듈의 기능을 조합하 여 논의 담수/비담수 상태에서의 물수지 및 물질수지를 재 현하기 위해 개발된 기법이다. Paddy-RCH는 논의 비담수 상태는 Paddy-PERLND Couple에서 모의하고 담수상태는 Paddy-RCHRES에서 모의하며 논을 담수상태로 유지시켜 작물을 재배하는 수도작의 경우 시비는 Paddy-RCHRES에 서 수행(PCS data)되며 논을 비담수상태 즉 밭의 기능으로 작물을 재배하는 경우는 Paddy-PERLND Couple에서 시비
(SPEC-ACTION module)가 이루어진다.

\subsection{HSPF Paddy-RCH 적용성 평가 시나리오}

$\mathrm{HSPF}$ Paddy-RCH기법의 적용성 평가는 관행시비 조건 대조구 $(\mathrm{CPF})$ 에서 보정과정을 거쳐 도출한 매개변수를 시비 량을 달리하는 2개의 필지논(SPF-1, SPF-2)과 2개의 광역논 (LPF 1, LPF 2) 지역에 확대 적용한 뒤, 모의된 결과와 현 장에서 조사된 실측자료를 비교하여 논으로부터 배출되는 유량, BOD, T-N, T-P 등 수질 모의에 대한 적용성을 평가하 였다.

적용성 평가를 위해 2개의 시나리오를 구성하였는데, 시 나리오 1 은 시비량을 달리하는 논에서의 적용성을 평가하 기 위함이고 시나리오 2는 다양한 영농방법이 복합적으로 이루어지는 광역논 유역에서의 적용성을 평가하기 위함이 다. 적용성 평가는 모의결과와 실측치의 $\mathrm{R}^{2}$ 와 \%difference를 이용하여 분석하였으며 분석지점은 시나리오 1 의 경우는 각 필지논의 배출구이며 시나리오 2 는 광역논 유역의 말단 인 $\mathrm{W} 1$ 과 $\mathrm{W} 2$ 지점이다.

\subsection{HSPF Paddy-RCH 구축}

구축에 필요한 기상자료는 대구기상대 시간별 강수량, 평 균기온, 풍속, 일사량 및 상대습도, 전운량 등을 수집하여 WDM (Watershed Data Management)에 database를 구축하 였으며 토지이용도는 환경부 환경공간정보서비스에서 제공 
Table 1. $\mathrm{R}^{2}$ value ranges for model performance.

\begin{tabular}{cccccccc} 
Criteria & \multicolumn{7}{c}{ Range } \\
$\mathrm{R}^{2}$ & & 0.6 & & 0.7 & & 0.8 & 0.9 \\
\hline Daily flows & Poor & Fair & & Good & Very good & $\rightarrow$ \\
\hline
\end{tabular}

Table 2. General calibration/validation targets or tolerances for HSPF application.

\begin{tabular}{cccc} 
Constituent & Very good & Good & Fair \\
Hydrology / Flow & $<10$ & $10 \sim 15$ & $15 \sim 25$ \\
\hline Water quality / Nutrients & $<15$ & $15 \sim 25$ & $25 \sim 35$ \\
\hline
\end{tabular}

Table 3. Hydrologic and water quality calibration parameters and possible ranges.

\begin{tabular}{|c|c|c|c|c|c|c|}
\hline \multirow{2}{*}{\multicolumn{2}{|c|}{ Parameter }} & \multirow{2}{*}{ Description } & \multirow{2}{*}{ Unit } & \multirow{2}{*}{ Model range } & \multicolumn{2}{|c|}{ This study } \\
\hline & & & & & Paddy & etc. \\
\hline \multirow{3}{*}{ Hydr. } & INFILT & Index to infiltration capacity & in/hr & $0.0001-100$ & 0.004 & $0.10-0.25$ \\
\hline & AGWRC & Base groundwater recession & none & $0.001-0.999$ & 0.98 & $0.94-0.97$ \\
\hline & DEEPFR & Fraction of GW inflow to deep recharge & none & $0.0-1.0$ & 0.001 & 0.2 \\
\hline \multirow{4}{*}{ W.Q. } & KBOD20 & Unit $\mathrm{BOD}$ decay rate at $20^{\circ} \mathrm{C}$ & $1 / \mathrm{hr}$ & 10-30-none & 0.0004 & $0.004-0.011$ \\
\hline & KODSET & BOD settling rate & $\mathrm{ft} / \mathrm{hr}$ & 0-none & 0.015 & $0.025-0.027$ \\
\hline & KTAM20 & Nitrification rates of ammonia at $20^{\circ} \mathrm{C}$ & $1 / \mathrm{hr}$ & 0.001-none & 0.0033 & 0.015 \\
\hline & KNO320 & Denitrification rates at $20^{\circ} \mathrm{C}$ & $1 / \mathrm{hr}$ & 0.001-none & 0.025 & 0.002 \\
\hline
\end{tabular}

하는 세분류 토지피복지도를 활용하였다.

소유역 구성은 $5 \times 5 \mathrm{~m}$ 의 수치고도모델(DEM; Digital Elevation Model)만으로는 농배수로 및 논의 구획을 명확히 반영하기 어려워 DEM 기반의 선행 BASINS/Delineation 을 수행한 뒤 이를 바탕으로 논 구획에 맞도록 수정하여 Predefined delineation 기법을 활용하였다.

\subsection{HSPF Paddy-RCH의 보정}

HSPF Paddy-RCH의 보정은 관행시비 대조구 $(\mathrm{CPF})$ 의 측 정자료를 이용하였으며 매개변수의 보정은 시행착오법으로 수행되었다. 이 방법은 모형의 다양한 변수를 변화시켜 상 관계수 및 결정계수 등의 최적점을 찾는 방법으로 반복횟수 가 충분할 경우 전체 근사 최적점에 도달 가능한 방법이나, 시간이 많이 소요된다는 단점이 있다. ${ }^{13)}$

모형효율 평가를 위한 결정계수는 유량의 경우 회귀선 이 실제 관측치를 어느 정도 대표하여 그 적합성을 보여주 고 있는가를 측정하는 계수인 결정계수 $\left(\mathrm{R}^{2}\right)$ 를, 수질의 경 우 모의치와 실측치의 차이를 두 값의 평균으로 나눈 값 (\%difference)을 사용하였으며 $\mathrm{R}^{2}$ 와 \%difference의 범위 및 목표치에 대한 일반적인 가이드라인은 Table 1, 2와 같다. ${ }^{14)}$

식 (1)과 (2)는 각각 $\mathrm{R}^{2}$ 와 \%difference의 관계식을 나타낸 다. 상관계수 $\mathrm{R}^{2}$ 는 1 에 가까울수록 구축된 모형의 정확도가 높음을 나타내고 있으며 \%difference는 0에 가까울수록 관 측값과 모의값이 유사함을 나타낸다.

$$
\begin{gathered}
R^{2}=\left[\frac{\sum_{i=1}^{n}\left(O_{i}-O_{\text {avg }}\right)\left(P_{i}-P_{\text {avg }}\right)}{\sqrt{\sum_{i=1}^{n}\left(O_{i}-O_{\text {avg }}\right)^{2} \sum_{i=1}^{n}\left(P_{i}-P_{\text {avg }}\right)^{2}}}\right]^{2} \\
\text { \%diff. }=\left(\sum_{i=1}^{n} O_{i}-\sum_{i=1}^{n} P_{i}\right) / \sum_{i=1}^{n} O_{i} \times 100
\end{gathered}
$$

여기서, $\mathrm{P}_{\mathrm{i}}$ 는 예측값, $\mathrm{O}_{\mathrm{i}}$ 는 실측값이며 $\mathrm{P}_{\mathrm{avg}}$ 는 예측값의 평균, $\mathrm{O}_{\mathrm{avg}}$ 는 실측값의 평균이고 $\mathrm{n}$ 은 자료의 수이다.

\section{3. 결과 및 고찰}

\section{1. 필지논의 Paddy-RCH 보정}

관행시비 조건 논(CPF)에서 측정된 자료를 이용하여 구축 된 HSPF Paddy-RCH를 보정하였다. 유출량 보정에 있어서 매개변수는 PWAT-PARM2 block의 Infilt (0.004)와 AGWRC (0.98), PWAT-PARM3 block의 DEEPFR (0.001)을 활용하였 으며, 수질은 BOD, T-N, T-P에 대하여 보정하였으며, 기본 적으로는 동일한 수준의 매개변수를 활용하도록 하였는데 $\mathrm{BOD}$ 의 경우, $\mathrm{BOD}$ 물질의 분해와 관련된 $\mathrm{KBOD} 20$, 침강을 통한 제거와 관련된 KODSET 인자를 사용하였으며, 일반 하천에서의 반응속도보다 분해속도를 낮추기 위해 활용되 었다. T-N과 T-P는 질산화와 관련된 KTAM 20 , 용출 및 확 산과 관련된 BRNIT(1), (2) 인자를 활용하였고, 전반적으로 하천보다 더딘 분해 및 반응속도를 구현하기 위해 활용되었 으며, 각 매개변수의 특징 및 적용범위는 Table 3과 같다. 


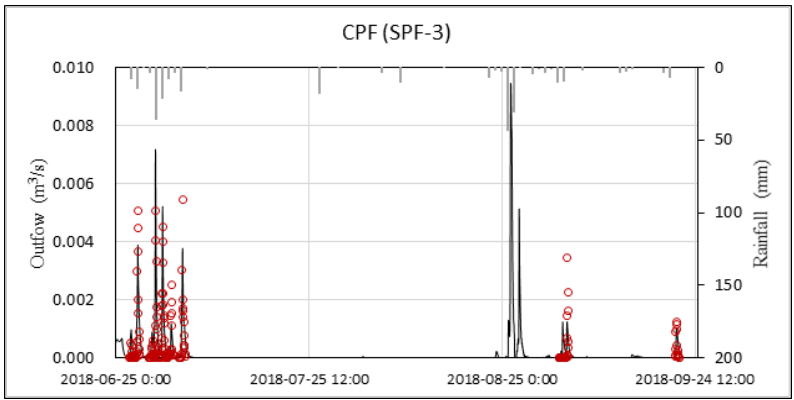

(a) Overflow

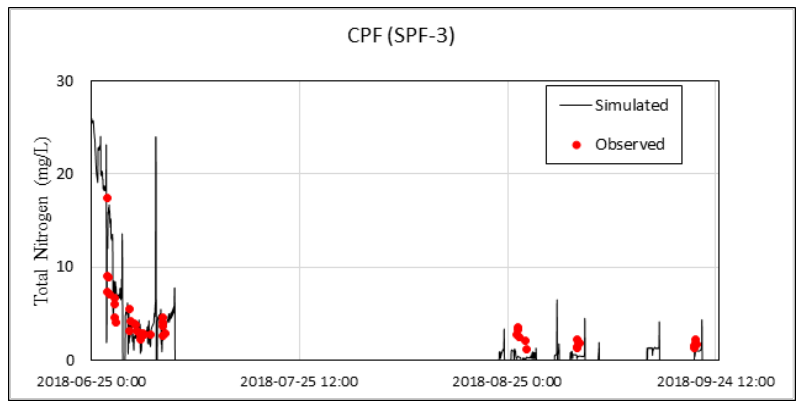

(c) $\mathrm{T}-\mathrm{N}$

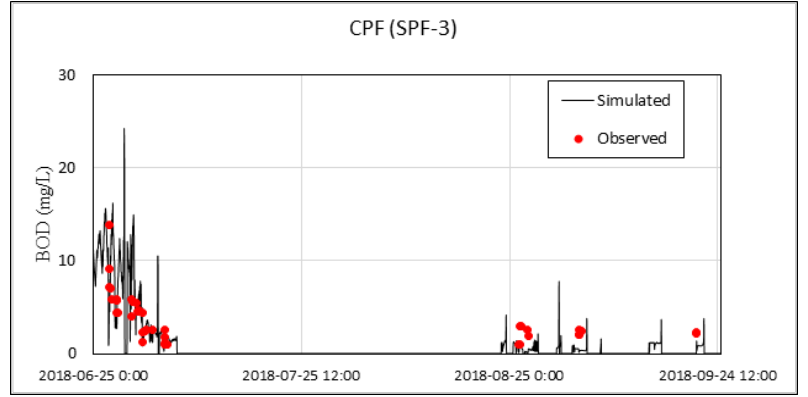

(b) BOD

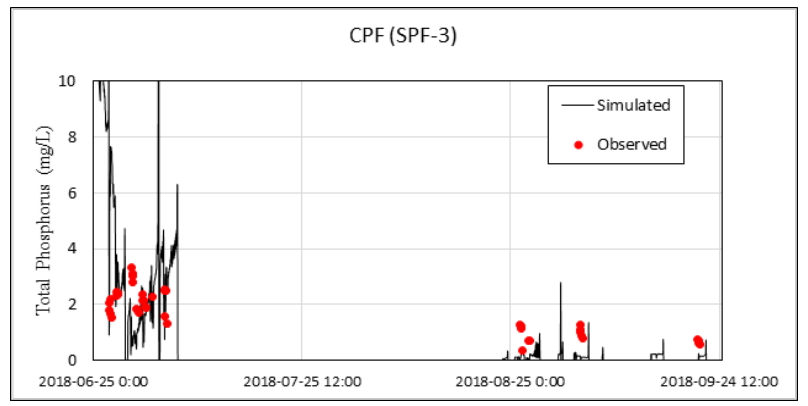

(d) T-P

Fig. 2. Calibration of flow and water-quality on control paddy field.

보정결과, 유량은 $\mathrm{R}^{2}$ 가 0.825 로 나타나 Very good으로 평 가되었으며 수질은 BOD, T-N, T-P 각각 \%difference가 7.52, $0.77,6.26$ 로 나타나 Very good으로 평가되어 유량과 수질 모두에서 모의치가 실측치를 비교적 잘 반영하고 있는 것으 로 판단된다(Fig. 2).

\section{2. 시나리오별 HSPF Paddy-RCH 적용성 평가}

\subsection{1. 시나리오 1 (시비량 변화)}

시비량을 달리하는 논에서 HSPF Paddy-RCH의 적용성을 평가하고자 구축한 필지논(SPF-1, SPF-2)에 관행시비 조건 논(CPF)에서 보정된 매개변수를 적용하여 유출 유량과 $\mathrm{BOD}, \mathrm{T}-\mathrm{N}, \mathrm{T}-\mathrm{P}$ 수질을 모의하였으며 모의한 결과와 현장에 서 측정된 실측치를 이용하여 시비량을 달리하는 논에서의 적용성을 평가하였다. 평가는 모의결과와 실측치의 $\mathrm{R}^{2}$ 와 $\%$ difference를 이용하였으며 분석결과는 Table 4와 같다.

$\mathrm{SPF}-1$ 의 유량은 $\mathrm{R}^{2}$ 가 0.713 으로 나타나 Good으로 평가 되었으며, 수질은 $\mathrm{BOD}, \mathrm{T}-\mathrm{N}, \mathrm{T}-\mathrm{P}$ 의 \%difference가 각각 (-)6.18, (-)10.32, 3.46로 나타나 모든 항목에서 Very good으 로 평가되었다. 한편, SPF-2의 유량은 $\mathrm{R}^{2}$ 가 0.689로 나타나
Fair로 평가되었으나, 수질은 BOD, T-N, T-P의 \%difference 가 각각 (-)12.20, (-)5.93, (-)5.26으로 나타나 대상 수질항목 모두 Very good으로, 시비량 변화에 대한 HSPF Paddy-RCH 모의결과의 현장 적용성이 높은 것으로 나타났다(Fig. 3).

HSPF Paddy-RCH 기법이 배수물꼬 높이를 달리하는 논 에서의 농업비점 배출량 모의에 대한 적용성이 높은 것으로 연구된 바 있으며 ${ }^{10)}$, 본 연구에서도 시비량을 달리하는 논 에서의 농업비점 배출량을 비교적 잘 모의하는 것으로 나타난 것으로 보아 다양한 농업비점 삭감시나리오 평가 시 HSPF Paddy-RCH 기법의 적용성이 높을 것으로 판단된다.

\subsection{2. 시나리오 2(광역논 유역)}

다양한 영농조건의 필지논에서 유출된 농업비점 배출수 와 유역으로부터의 비점오염 유출수가 모이는 광역논 유역 에서 $\mathrm{HSPF}$ Paddy-RCH의 적용성을 평가하고자, 관행시비 조건 논(CPF 조건)에서 보정된 매개변수를 적용하여 유출 유량과 BOD, T-N, T-P 수질을 모의하였으며, 모의한 결과와 현장에서 측정된 실측치를 이용하여 시비량을 달리하는 논 에서의 적용성을 평가하였다. 평가는 모의결과와 실측치의

Table 4. Evaluation result of HSPF Paddy-RCH applicability in paddy field (SPF-1, SPF-2).

\begin{tabular}{cccccccccc} 
& \multicolumn{3}{c}{ Flow } & \multicolumn{3}{c}{ BOD } & \multicolumn{3}{c}{ T-N } \\
& $R^{2}$ & Eval. & \% diff. & Eval. & \% diff. & Eval. & \% diff. & Eval. \\
SPF-1 & 0.713 & Good & $(-) 6.18$ & Very G. & $(-) 10.32$ & Very G. & 3.46 & Very G. \\
\hline SPF-2 & 0.689 & Fair & $(-) 12.20$ & Very G. & $(-) 5.93$ & Very G. & $(-) 5.26$ & Good \\
\hline
\end{tabular}

* \%diff.; \%difference, Eval.; Evaluation, Very G.; Very Good 


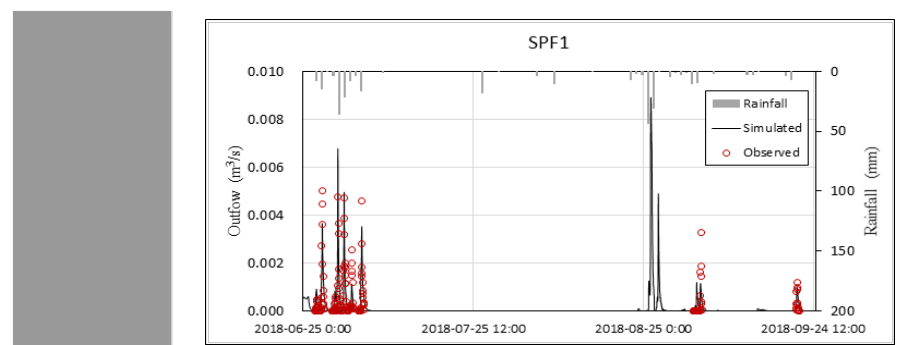

(a) Flow

SPF-1

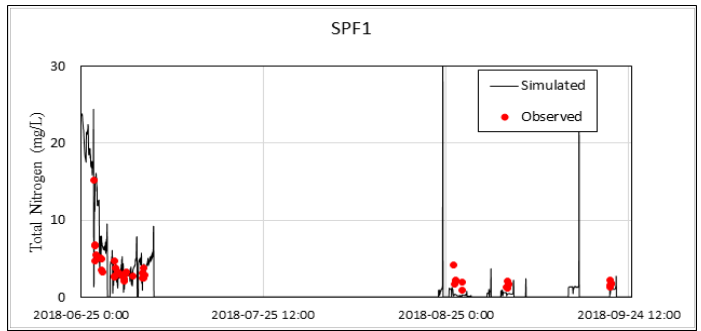

(c) $\mathrm{T}-\mathrm{N}$

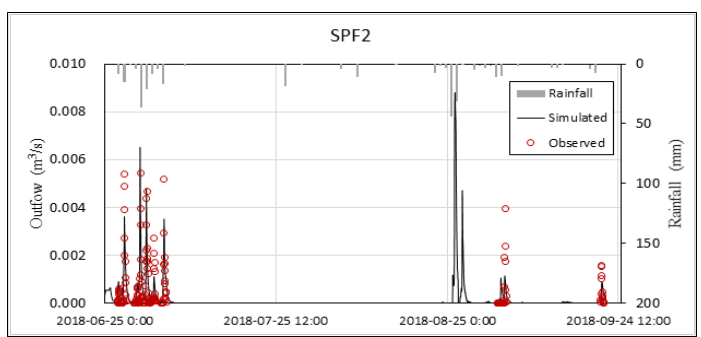

(e) Flow

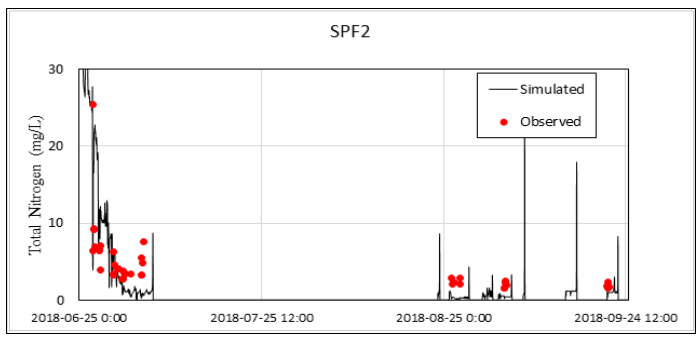

(g) T-N

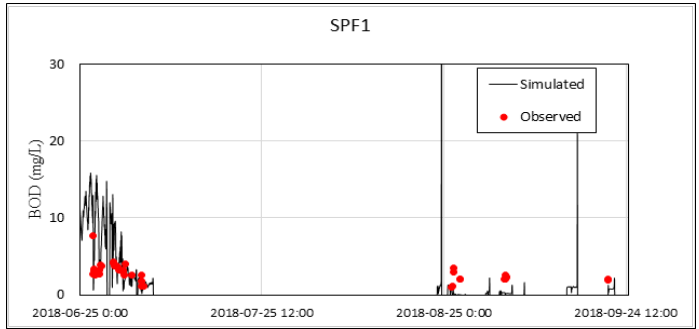

(b) BOD

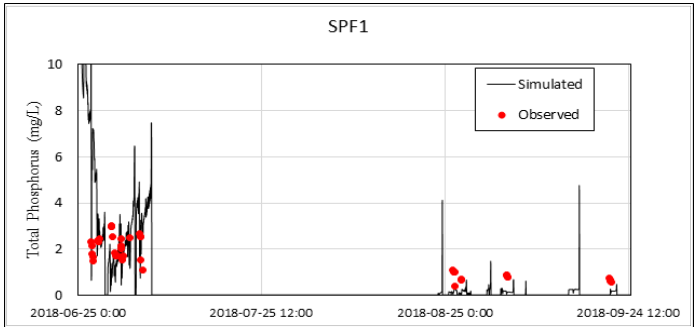

(d) T-P

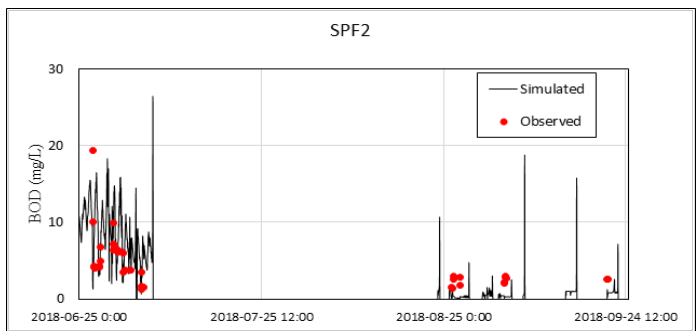

(f) BOD

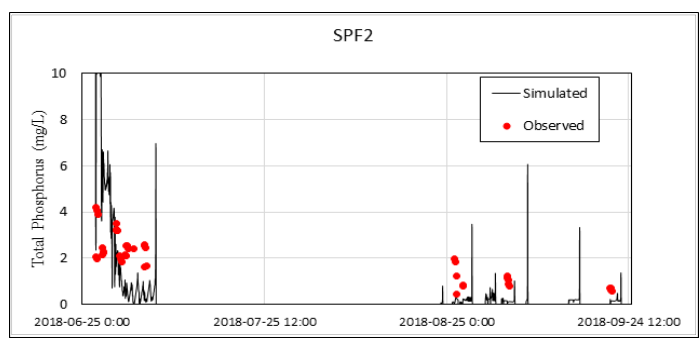

(h) T-P

Fig. 3. Comparison of simulated and observed data at outlet of each paddy field.

Table 5. Evaluation result of HSPF Paddy-RCH applicability in watershed (W1, W2).

\begin{tabular}{ccccccccc} 
& \multicolumn{3}{c}{ Flow } & \multicolumn{3}{c}{ BOD } & \multicolumn{3}{c}{ T-N } & & T-P \\
& $R^{2}$ & Eval. & \% diff. & Eval. & \% diff. & Eval. & $\%$ diff. & Eval. \\
\hline W1 & 0.720 & Good & $(-) 9.76$ & Very G. & 14.15 & Very G. & $(-) 8.60$ & Very G. \\
\hline & 0.693 & Fair & 19.29 & Good & $(-) 7.13$ & Very G. & $(-) 8.08$ & Very G. \\
\hline
\end{tabular}

* \%diff.; \%difference, Eval.; Evaluation, Very G.; Very Good

$\mathrm{R}^{2}$ (유출량)와 \%difference(수질)를 이용하였으며, 분석결과

는 Table 5와 같다.

$\mathrm{W} 1$ 의 유량은 $\mathrm{R}^{2}$ 가 0.720 로 나타나 Good으로 평가되었으며 수질은 BOD, T-N, T-P의 \%difference가 각각 (-)9.76, 14.15, (-)8.60으로 나타나 모든 항목에서 Very good으로 평가되었다.
$\mathrm{W} 2$ 의 유량은 $\mathrm{R}^{2}$ 가 0.693 으로 나타나 Fair로 평가되었으나, 관측치의 수가 적고 월류하는 특정 시간대만 관측된 자료인 점을 고려하면, 합리적 수준인 것으로 판단된다. 수질은 BOD, T-N, T-P의 \%difference가 각각 19.29, (-)7.13, (-)8.08 로 나타나 모든 항목에서 Good 이상으로 평가되어 시비량 변 


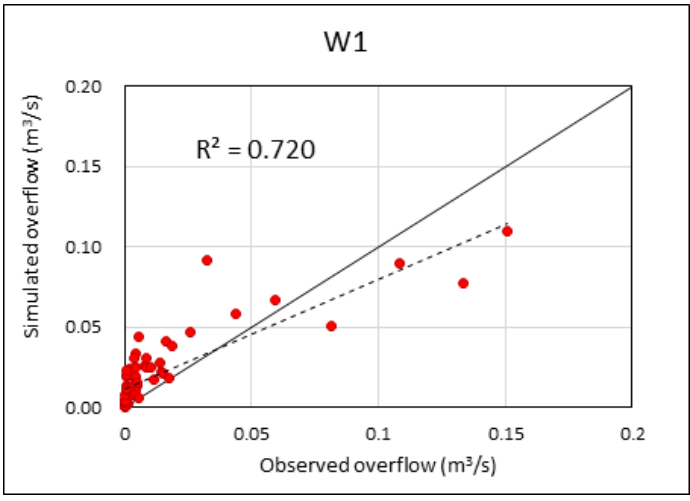

(a) LPF1

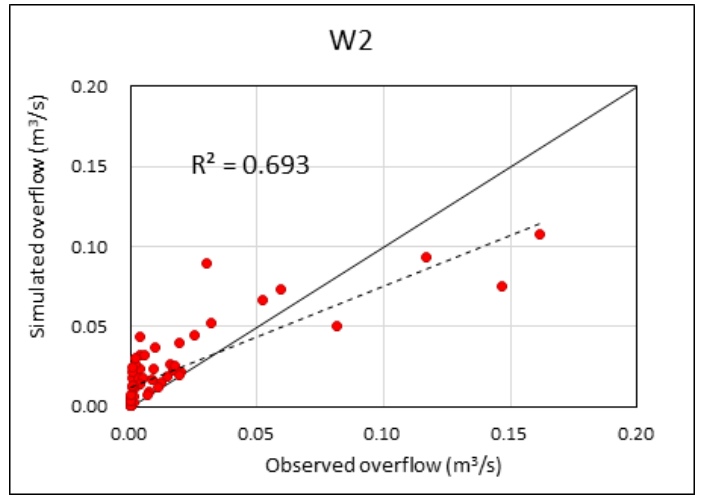

(b) LPF2

Fig. 4. Comparison of observed and simulated overflows.

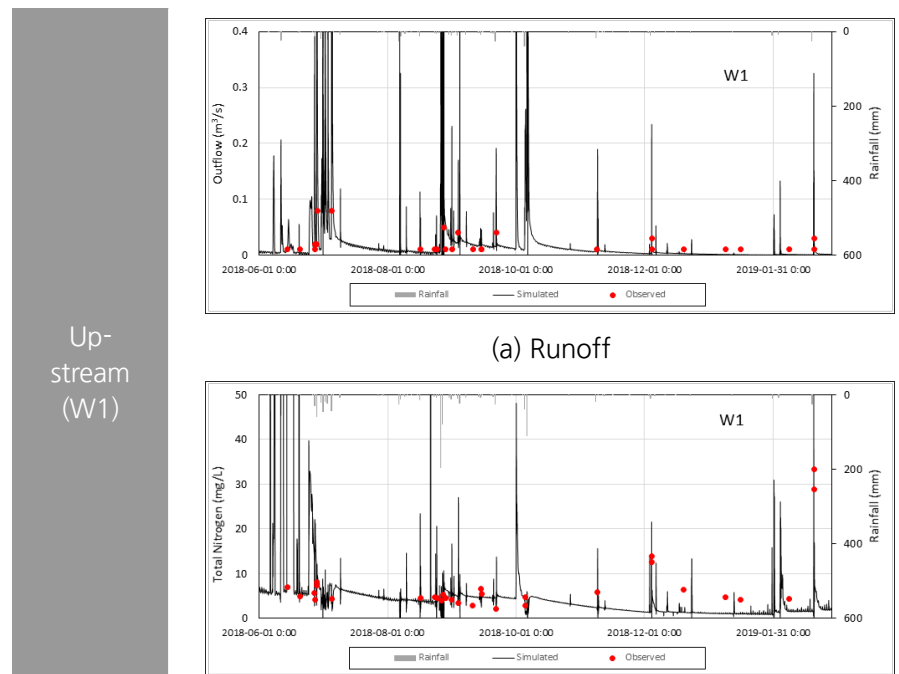

(c) T-N

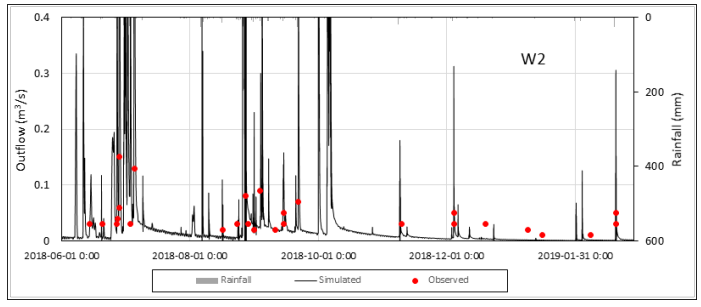

(a) Runoff

stream

(W2)

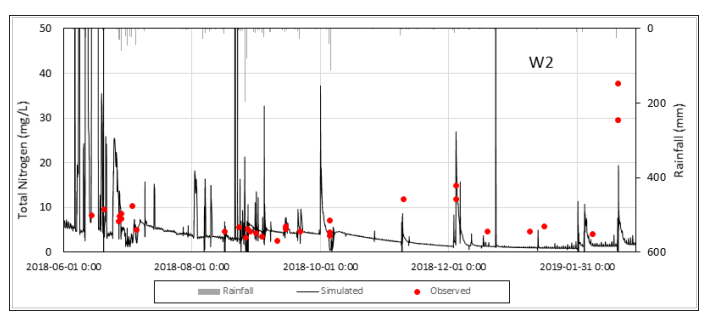

(c) $\mathrm{T}-\mathrm{N}$

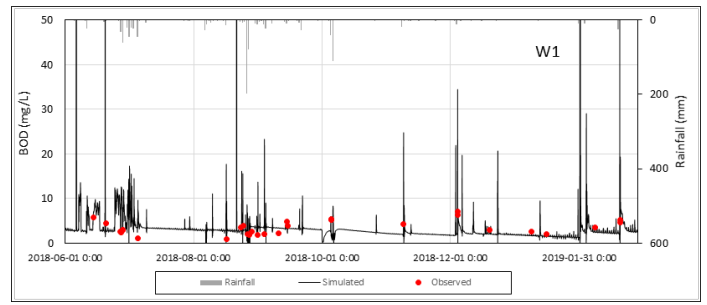

(b) BOD

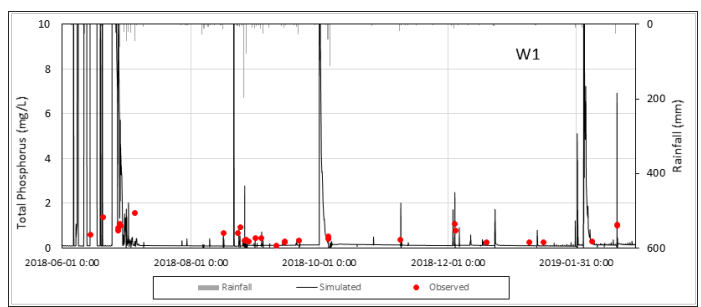

(d) T-P

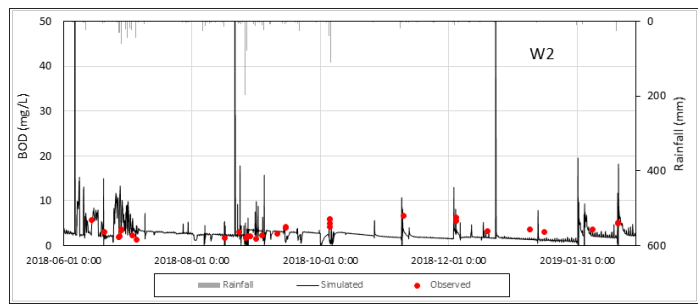

(b) BOD

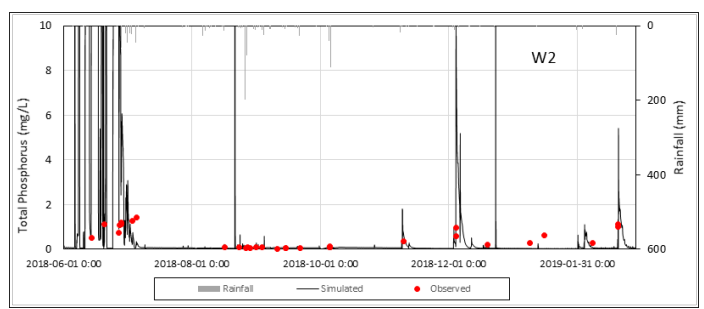

(d) T-P

Fig. 5. Comparison of simulated and observed data of watershed (at W1, W2).

화에 대한 재현성이 높은 것으로 나타났다(Fig. 4,5).

HSPF Paddy-RCH 기법이 배수물꼬 높이, 시비량을 달리
하는 필지논 뿐만 아니라 다양한 배출원이 포함된 유역단위 의 배출량도 비교적 잘 모의하는 것으로 나타나 영농조건에 
따른 논의 수질개선효과 및 총량관리 삭감부하량 산정에 효 과적인 도구로 사용할 수 있을 것으로 판단된다.

\section{4. 결론}

본 연구는 낙동강수계 계성천에 위치한 논(대조구)에서 측 정된 물수지 및 물질수지 자료를 이용하여 HSPF Paddy-RCH 모델을 보정하고, 보정된 반응계수를 시비량을 달리하는 2 개의 필지논과 2 개의 광역논 유역에 적용하여 모의결과를 측정자료와 비교함으로써, 농업비점 삭감량 평가를 위한 $\mathrm{HSPF}$ Paddy-RCH 모델의 적용성을 평가하여 농업비점 저 감방법에 따른 삭감부하량 산정을 위한 기초자료를 제공하 고자 하였으며 그 결과는 다음과 같다.

1) HSPF Paddy-RCH 기법을 이용하여 모델을 구축 후 관 행시비 조건인 필지논(대조구)을 대상으로 단순시행 착오법 으로 보정을 실시하였으며, 보정 결과 $\mathrm{R}^{2}$ 와 \%difference의 범위 가이드라인에 따라 유량, BOD, T-N, T-P 모두 Very $\operatorname{good}$ 으로 평가되어 모의치가 실측치를 비교적 잘 반영하는 것으로 나타났다.

다만, 보정 시 낮은 시간 해상도의 수질데이터(사용된 관 측치)로 인해 수체의 수질 현황을 전부 반영하지 못하여 이 에 따른 오차가 발생했을 것으로 보이며, 정확한 모의를 위 해 보다 높은 시간해상도의 보정 데이터(관측치)가 필요할 것으로 판단된다.

2) 보정된 매개변수를 시비량을 달리 하는 2 개의 필지논 과 광역논 유역에 확대 적용한 결과 논에서 배출되는 유량 과 BOD, T-N, T-P 등 수질을 합리적 수준에서 모의할 수 있 는 것으로 나타나 논 및 농업유역에서 농업비점 삭감량 분 석을 위한 HSPF Paddy-RCH 모델의 적용성이 높은 것으로 판단된다.

3) 대표 필지논을 대상으로 HSPF Paddy-RCH 모델을 보 정하여 매개변수를 결정한 뒤 결정된 매개변수를 인근 또는 유사 농업지역에 확대 적용하여 농업비점 삭감시나리오를 분석하더라도 비교적 합리적 결과를 도출할 수 있을 것으로 기대된다.

4) 농업비점오염 삭감량 산정을 위한 HSPF Paddy-RCH 모델의 적용성을 평가한 해당 연구는 장기적 모니터링이 필 요한 농업비점오염원 저감시설의 비점오염원 저감효율을 정량적으로 평가할 수 있는 방법으로 사용할 수 있을 뿐만 아니라 농경지가 많은 농촌 유역에서의 다양한 농업비점 $\mathrm{BMP}$ 적용에 따른 수질개선효과 및 총량관리 삭감량 산정 에 사용할 수 있을 것이라 사료된다. 다만, 논에서의 물수지 및 물질수지는 강우, 관개, 기온, 시비량, 영농특성 등 다양 한 요인에 달라지나 본 연구는 특정지역에 한정된 연구결과 이므로 보다 많은 연구가 수행되어야 할 것으로 판단된다.

\section{References}

1. National Institute Environmental Research, Nakdong River Water System Total Water Pollution Management Stage Evaluation Report, National Institute Environmental Research(2017).

2. Ministry of Environment, A Quantification Study on the Reduction Effect of Agricultural Non-point Source Pollution in Rural Areas, ME(2014).

3. Rural Research Institute, Development of Improved Farming Methods for Agricultural Non-point Source Pollution Reduction, RRI(2015)

4. C. K. Yoon, J. Y. Han, K. W. Jung, J. H. Jang, Application of BASINS/WinHSPF for pollutant loading estimation in Soyang Dam watershed, Korean J. Limnol., 40(2), 201-213 (2007).

5. M. S. Kang, Development of improved farming method to reduce agricultural nonpoint source pollution, Rural Resources, 52(4), 40-50(2010).

6. E.-J. Lee, H.-K. Kim, S.-W. Park, Assessing impact of non-point source pollution by management alternatives on arable land using AGNPS model, J. Agric. Life Sci., 41(4), 55-61(2007).

7. K.-H. Han, Estimation of the pollutant loads from paddy fields by cultivation practices using a non-point-source model, Korean J. Environ. Agric., 27(1), 10-17(2008).

8. J.-H. Song, M.-S. Kang, I.-H. Song, J.-R. Jang, Comparing farming methods in pollutant runoff loads from paddy fields using the CREAMS-PADDY model, Korean J. Environ. Agric., 31(4), 318-327(2012).

9. D. G. Lee, J.-H. Song, J. H. Ryu, J. N. Lee, S.-K. Choi, M. S. Kang, Integrating the mechanisms of agricultural reservoir and paddy cultivation to the HSPF-MASA-CREAMS-PADDY system, J. Korean Soc. Agric. Eng., 60(6), 1-12(2018).

10. S. H. Jung, H.-P. Rhee, H. S. Hwang, C. G. Yoon, Study on development of Paddy-RCH method to consider discharge characteristics of paddy field in watershed model HSPF, J. Korean Soc. Environ. Eng., 41(6), 311-320(2019).

11. KECO, Pilot Project on Application and Expansion of Optimal Management Techniques for Non-Point Sources Pollution Management in Rural Areas, KECO(2019).

12. National Institute Environmental Research, The Empirical Study on Agricultural Non-point Source Pollution Reduction for TMDL(Total Maximum Daily Load), National Institute Environmental Research(2019).

13. S. C. Lee, D. C. Shin, Performance comparison of genetic algorithm and trial-and-error method in the member size optimization, Journal of the Architectural Institute of Korea Structure \& Construction, 25(10), 3-10(2009).

14. A. S. Donigian, Lecture \#19, Calibraion and Verification Issures, HSPF Training Workshop Handbook and CD, Office of Science and Technology, US EPA, Washington, D. C., USA, 19-22(2000). 


\section{Authors}

\section{Shin Hye Jung}

Department of Environmental Health Science, Konkuk University, Ph.D. Candidate, ORCID (0) 0000-0002-3449-7743

\section{Han-Pil Rhee}

Department of Environmental Health Science, Konkuk University, Ph.D., Adjunct Professor, ORCID (10 0000-0003-2519-1547

\section{Ha Sun Hwang}

Water Environmental Research Department, National Institute of Environmental Research, Ph.D., Researcher, ORCiD 시 0000-00026340-9001

\section{Chun Gyeong Yoon}

Department of Environmental Health Science, Konkuk University, Professor, ORCID (1) 0000-0003-2942-2197 